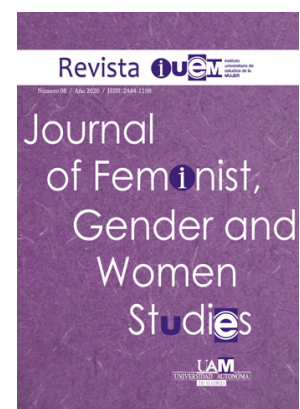

Recibido: 04/02/2020

Aceptado: 01/05/2020

\section{La representación de los géneros en el Imperio Romano del siglo I y su impacto social hoy}

\author{
The representation of genders in the Roman Empire of the $1^{\text {st }}$ century \\ and its social impact today \\ María Nely Vásquez Pérez ${ }^{1, @ y ~ M i g u e l ~ R a m o ́ n ~ V i g u r i ~ A x p e ~}{ }^{1}$ \\ ${ }^{1}$ Universidad de Deusto, Facultad de Teología del Norte de España, sede de Vitoria-Gasteiz. \\ $@$ Autor/a de correspondencia: nelvasper@gmail.com
}

\title{
Resumen
}

El objetivo de esta investigación es analizar, a partir de la cultura visual aplicada a la iconografía imperial de Roma, la representación de los géneros en los contextos posbélicos de la Roma Imperial del siglo I y su impacto social hoy. Se visibiliza que el género masculino está vinculado al poder y al dominio mediante unas imágenes, y, que, por el contrario, la mujer es excluida de la vida social mediante una representación en la que su cuerpo es utilizado por el imperio como "símbolo natural" de las naciones conquistadas y sometidas. Dichas imágenes y representaciones se utilizan, porque producen -por el poder evocativo y performativo del lenguaje visual- determinados esquemas jerárquicos, legitimadores del dominio imperial y de la sumisión de los pueblos vencidos.

Palabras clave: Representación visual de los géneros, cultura visual, legitimación del poder, cosificación del cuerpo femenino, performatividad del lenguaje visual.

\begin{abstract}
The objective of this research is to analyze, from the visual culture applied to the imperial iconography of Rome, the representation of genres in the post-war contexts of Imperial Rome in the $1^{\text {st }}$ century and their social impact today. It is made visible that the masculine gender is linked to power and dominance through images and that, on the contrary, women are excluded from social life through a representation in which their body is used by the empire as a "natural symbol" of the conquered and subdued nations. Said images and representations are used because they produce -by the evocative and performative power of visual language- certain hierarchical schemes, legitimizing imperial dominance and the submission of defeated peoples.
\end{abstract}

Keywords: Visual representation of genders, visual culture, legitimation of power, reification of the female body, performativity of visual language. 


\section{INTRODUCCIÓN}

Tema

Mediante la metodología de la cultura visual aplicada a la iconografía imperial de Roma, se constata la representación dicotómica y opuesta de los géneros en los contextos posbélicos de la Roma Imperial del siglo I y su impacto social a favor de una estructura patriarcal claramente dominante e incuestionable por la evidencia que desprenden las imágenes utilizadas. Se visibiliza el género masculino como naturalmente vinculado al poder y dominio mediante unos símbolos muy concretos y, por el contrario, la mujer es excluida e invisibilizada mediante una representación en la que su cuerpo es utilizado por el imperio como "símbolo natural" de las naciones conquistadas y sometidas. Dichas imágenes y representaciones se utilizan porque producen determinados esquemas jerárquicos, legitimadores del dominio imperial y de la sumisión de los pueblos vencidos.

\section{Justificación}

La relevancia de la presente investigación radica en la importancia del carácter performativo del lenguaje visual cuando es manejado ideológicamente por el poder dominante. Las imágenes o iconos del poder que las usa, producen ipso facto aquello que evocan. Por ello, son un instrumento altamente eficaz del control de los pueblos sometidos y de una construcción social de los géneros que perpetúe las estructuras patriarcales. Pero lo verdaderamente interesante del estudio es que, dichos mecanismos simbólicos de sometimiento, dominio y exclusión de la mujer, siguen siendo, en esencia, los mismos hoy en día. La labor crítica y deconstructiva de dichas imágenes mediante una cultura visual adecuada es, pues, de capital importancia para avanzar en la construcción de una sociedad más paritaria y justa para con las mujeres (multisecularmente excluidas e invisibilizadas).

\section{MÉTODO}

\section{Hipótesis}

Este trabajo plantea (se comprenderá mejor cuando se analicen las representaciones visuales "oficiales" del imperio romano, de tipo iconográfico, etc.) las siguientes interrogaciones: ¿qué significado se da a los cuerpos femeninos, en el marco de los contextos bélicos o de conflictos territoriales, que hace posible que sean percibidos como "símbolo natural" de las naciones conquistadas y sometidas? ¿Y qué consecuencias tienen para las mujeres reales dichas equivalencias? ¿Por qué el cuerpo de la mujer es "símbolo natural" de conquista, dominio y sumisión? La cuestión es relevante, actual y acuciante, porque no podemos olvidar que, en los asedios y las guerras, la violación de las mujeres ha sido, y sigue siendo, un modo simbólico -y casi ritual- de demostrar la supremacía de los vencedores sobre los vencidos.

\section{Metodología de trabajo: Género y representación visual}

Las imágenes o representaciones visuales son lenguaje y, por ello, espacios de identificación, significación y subjetivación. El sujeto siempre está simultáneamente situado en o por el discurso y construido en o por el discurso; también el discurso visual. De ahí que la representación visual no es casual ni neutral, sino que constantemente trabaja para normalizar y definir a los sujetos, a los que posteriormente otorgará una identidad e insertará en una categoría (Caballero, 2004).

Las imágenes ofrecen un nuevo panorama teórico que permite abordar las construcciones identitarias en un contexto social determinado; así como una serie de herramientas metodológicas, alternativas, que posibilitan analizar las múltiples y complejas representaciones de género ${ }^{1}$. Sobre la relación género-cultura visual, la bibliografía es a estas alturas amplísima. Como un trabajo clásico y de carácter general, todavía de plena actualidad, cabe citar la obra de Parker y Pollock sobre las mujeres el arte y la ideología².

Las distintas representaciones visuales, al igual que el lenguaje, no son neutrales, sino que están atravesadas por diferentes contenidos ideológicos y condicionamientos socioculturales que influyen en la configuración de las identidades; o sea, en la definición y estereotipos identitarios. En un sentido análogo al que planteamos en este trabajo (aunque se trate, obviamente de un contexto social y cultural muy distinto), Mercedes Alcalá Galán (Universidad de Wisconsin-Madison), en un artículo del año 2012, analiza la ideología de la violencia sexual contra la mujer mediante la interpretación de diversos cuadros de Rubens, así como de otras obras de arte, y concluye que dichas representaciones del cuerpo femenino subyugado tienen como finalidad exaltar y mitificar la superioridad del varón, consolidando la estructura patriarcal ${ }^{3}$. Dicho trabajo es similar en el planteamiento al ya clásico de Margaret D. Carroll: "La erótica del absolutismo. Rubens y la mitificación de la violencia sexual"4.

La cultura visual crítica muestra que las violencias contra las mujeres en un sistema de poder socio-sexual y político patriarcal, de contexto imperial, se nutren de las relaciones de subordinación, opresión, exclusiones e inequidades, y del juego de relaciones de poder entre los sexos (Guasch, 2004). La categoría de género ha sido una herramienta analítica fundamental para la comprensión de las relaciones de poder entre varones y mujeres; así como del entramado cultural que sustenta las concepciones y prácticas -beneficiosas para el poder patriarcal- acerca de lo femenino y lo masculino, asignando roles y estatus para cada uno de ellos: espacios de poder para los varones y espacios de subordinación y opresión para las mujeres (Butler, 2007).

\section{El cuadro de Greimas y la interpretación visual}

La investigadora de origen estadounidense Davina López sostiene que la oposición jerárquica de los géneros

\footnotetext{
1 Ver Robbins y Melion, 2017.

2 Parker y Pollock, 2013.

3 Alcalá Galán, 2012.

4 Carroll, 1989.
} 
expresada en las imágenes es descrita por el contraste asimétrico del "cuadro semiótico" de Greimas. Dicho autor estructuró las relaciones de unos sobre otros a través de binarismos opuestos (López, 2008). Según Greimas, el significado cultural se produce por una elaboración compleja de posibilidades lógicas que contiene la relación entre una oposición binaria y sus estructuras de negación y afirmación (Greimas y Courtés, 1982: 96-97). Así, por ejemplo, el par supuestamente opuesto "hombre" y "mujer" genera un campo de oposición fáctica.

Según la noción greimasiana del rectángulo semiótico, la cultura y el conocimiento se organizan a partir de oposiciones semánticas entre lo masculino/femenino, individuo/colectivo, vida/ muerte, entre otros. La diferencia entre dos cosas genera una oposición básica entre dos términos (así como A se opone a su contradictorio No-A). A partir del análisis del diagrama semiótico, López descubre que la jerarquía o asimetría entre los géneros en el contexto imperial es una manifestación de la bipolaridad inherente de la estructura lógica del pensamiento occidental, fundada sobre el dualismo y dicotomización de la realidad. La autora visualiza esta jerarquización greimasiana en el siguiente gráfico:

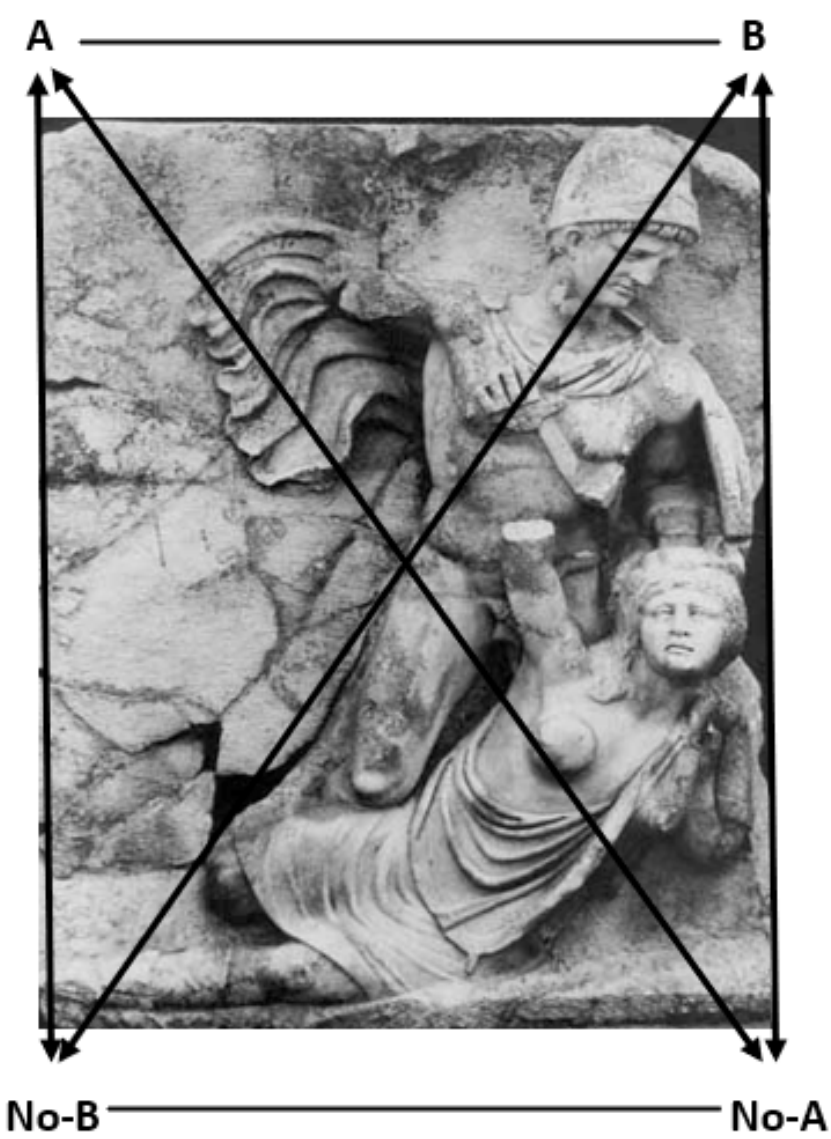

Figura 1. El diagrama semiótico es como un mapa que revela el poder de las relaciones jerárquicas. A y $B$ significan la posición dominante. Sin embargo, $A$ y $B$ definen y son definidos sobre no-A y no-B, que representan no solo la oposición de $\mathrm{A}$ y $\mathrm{B}$, sino también la posición subordinada. Espacialmente, Claudio sometiendo a Britania es una expresión sucinta de las relaciones jerárquicas. Fuente: Davina López (2008: 21).
El pensamiento oposicional de la tabla de Greimas tenía como fuente común la tabla de Pitágoras que fue usada por Platón y Aristóteles. Así, Aristóteles, en su obra Metafísica, recoge la tabla de los diez principios opuestos planteados por los pitagóricos (Met. 986a 25): límiteilimitado, impar-par, unidad-pluralidad, derecho-izquierdo, macho-hembra, en reposo-en movimiento, recto-curvo, luzoscuridad, bueno-malo, cuadrado-rectángulo.

Entre el abundantísimo corpus visual de la Roma imperial del siglo I, se han tenido que escoger unas pocas imágenes, ya que una presentación visual más exhaustiva excede las posibilidades de este artículo. El criterio de selección de las imágenes ha sido la mayor explicitud en la presentación dicotómica varón-mujer, victorioso-derrotada, dominador-sometida; así como otros elementos que hacen referencia a la disposición física (varón erguido-mujer en el suelo), y a la violencia contra la mujer (varón amenazando con la espada a la mujer). La selección realizada también pretende facilitar la utilización del cuadro de Greimas, posibilitando así una cultura visual más clarificadora, en orden a mostrar cómo esas imágenes contribuyen a construir y consolidar la dinámica de dominio/sumisión a lo largo de toda la tradición occidental posterior (hasta llegar a nuestros días).

La tabla pitagórica de los principios dualistas nos ofrece una visión importante de la concepción que se tenía de la mujer en relación con el varón. Estas dicotomías no son simétricas o equivalentes, sino que se construyen atribuyendo valores positivos a unos elementos y negativos a otros ${ }^{5}$. Según esta lógica, el varón aparece en la lista de principios positivos; la mujer, por su parte, aparece como inferior al varón por naturaleza. Este contraste se utiliza para asignar a los varones un mayor estatus y justificar su ejercicio de poder sobre las mujeres. En este sentido, se puede apuntar que la estructura dualística de las imágenes imperiales es una utilización ideológica de las oposiciones jerárquicas tal y como son formuladas por la filosofía aristotélica ${ }^{6}$.

Sin embargo, desde una visión crítica y reconstructiva, podemos ver que en algunas imágenes las mujeres no solo aparecen en posición derrotada, sino que también aparecen victoriosas y triunfantes en los espacios públicos y monedas ${ }^{7}$. Pero, eso sí, siempre en determinados contextos legitimadores de la preeminencia del varón.

A modo de ejemplo, la diosa Victoria aparece en el reverso de una moneda en la época de Constantino II representada como una mujer alada, habitualmente en actitud de ceñir una corona de laurel a los vencedores y césares. La diosa Victoria simbolizaba el triunfo sobre la

\footnotetext{
5 Ver Prudence, 1985. La autora explica la diferencia entre sexo y género, la relación del concepto de la mujer en relación con el concepto del varón, y, por último, aborda el desarrollo de las teorías de la complementariedad.

6 Aristóteles representa la bipolaridad entre el varón y la mujer, entre lo superior y lo inferior, entre lo bueno y lo malo. Los términos dominantes eran el varón, lo superior, lo bueno; en cambio, lo inferior era lo femenino, lo inferior, lo malo. Según Brigitte Kahl (2020: 19), el mundo cósmico está divido por la oposición de contrarios: Superior: varón - forma - alma activo - sustancia - uno. Inferior: mujer - materia - cuerpo - pasivo accidente - otro.

7 Existe un material arqueológico que permite destacar la trascendencia de las figuras femeninas, aunque por descontado esta posición no fuese uniforme a lo largo del imperio: Bauman, 1994; Bartman, 1999; Wood, 1999; Domínguez, 2010; Beckman, 2012.
} 
muerte y su papel era recompensar a los vencedores en batalla. Fue considerada como una de las diosas favoritas de los líderes militares romanos que regresaban de la guerra.

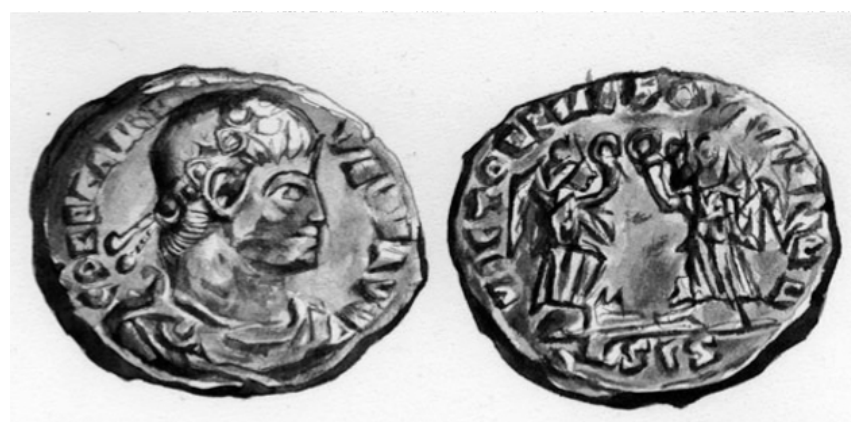

Figura 2. Dos Victorias enfrentadas en el reverso de una moneda en la época de Constantino II sosteniendo coronas de laurel. Fuente: Alberto González (2001: 124).

Del mismo modo, las mujeres aparecen reflejadas como personajes divinos, vinculadas a la fecundidad y esplendor de la naturaleza. En uno de los dos relieves que decoran la parte posterior del Ara Pacis Augustae ${ }^{8}$, se encuentra Tellus (aunque por su iconografía se podría relacionarse con las diosas Paz o Venus). Tellus, como divinidad de la tierra, aparece representada como la imagen de la prosperidad, la paz y la abundancia, traídas por Augusto como príncipe benefactor del pueblo romano (Zanker, 1992: 208-212). El emperador asimila los elementos propios del género femenino para hacer más universal su poder (Martínez López, 1998: 258). La diosa aparece rodeada de frutas, espigas y flores. Lleva en el pelo una corona de espigas y amapolas y, bajo ella, animales domésticos. En su regazo sostiene a dos juguetonas criaturas en sus brazos, las cuales se empeñan por alcanzar sus pechos. En la sociedad romana, la construcción del género femenino/masculino crea esta dicotomía de forma similar a otras sociedades patriarcales, donde mujeres y varones juegan papeles asimétricos, en este caso, ante la guerra (violencia) y la paz. Los dioses representan y reproducen la realidad, en cuanto son el reflejo idealizado de la realidad (Martínez López, 1998: 261).

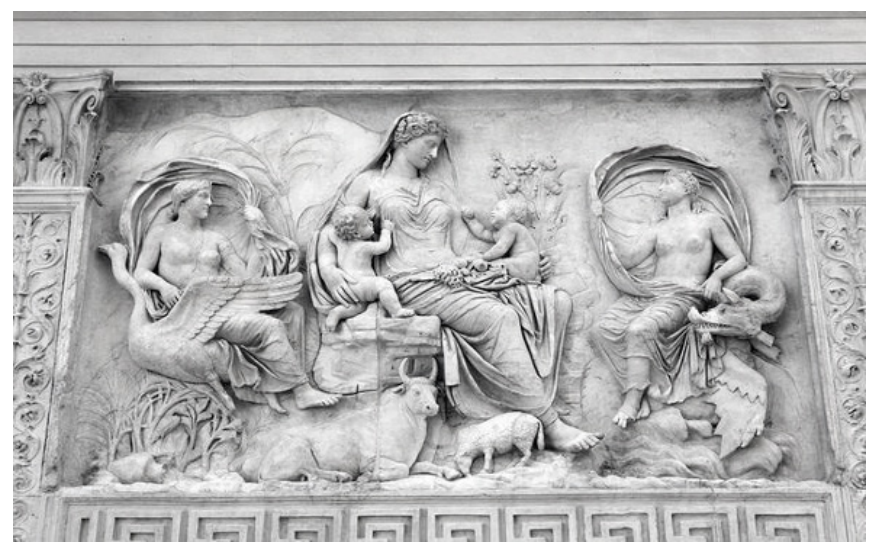

Figura 3. Ara Pacis Augustae, relieve de Tellus. Fuente: Zanker (1992: 209).

8 El Ara Pacis Augustae constituye uno de los monumentos más emblemáticos de la antigüedad romana con el que Augusto trató de legitimar su nuevo régimen. A través del programa iconográfico de los relieves, el emperador buscó enlazar su política a los orígenes y tradiciones del pueblo romano, uniendo el pasado mítico y el presente.

\section{DISCUSIÓN}

\section{La representación de los géneros en el contexto imperial}

El espacio reproduce el orden de los valores de una sociedad, las jerarquías sociales y el rol que juegan las mujeres y los varones, estableciendo límites fronterizos, determinando quién pertenece al lugar y quién queda excluido (Páramo y Burbano, 2011). En la Antigüedad clásica, el espacio público fue uno de los lugares donde se representaba y visibilizaba la legitimación de la colonización territorial romana, a través de un sistema semántico de representación visual. Dicho sistema, a través de imágenes, permitía canalizar el universo simbólico ideológico de la política imperial, mostrando su poder como algo evidente e incuestionable ${ }^{9}$.

Este sistema visibilizaba las representaciones de género de la élite y la no élite, así como, también, la creación y el mantenimiento de la construcción de la realidad imperial romana: el poder y el privilegio expandido sobre las naciones conquistadas. Mediante una red de imágenes muy estudiadas y elaboradas, el imperio romano construyó una realidad homogeneizante y totalizadora del mundo.

Uno de los monumentos religiosos más importantes dedicado al emperador Augusto, que establecía de forma jerárquica la representación de los géneros, fue el Sebasteión de Afrodisias ${ }^{10}$. Se trata de un espacio lleno de imágenes, donde los habitantes podían contemplar la majestuosidad y el poderío del emperador durante la conquista romana. Esta auto-representación del Imperio en imágenes y monumentos servía como una pedagogía para mantener el poder y el control social de los pueblos sometidos (López, 2007: 134-135). A continuación, vamos a analizar cómo estaban representados los géneros en dichas imágenes.

\section{La representación femenina}

En el relieve (Fig. 4) se puede apreciar a Claudio, emperador de Roma, entre el 41 y el 54 d. C., sometiendo a Britania (uno de los territorios conquistados por Roma, al norte de la actual Francia), representada por el cuerpo de una mujer semidesnuda pidiendo clemencia desde el suelo. Claudio está de pie, desnudo, cubierto por una capa hinchada por el viento y un casco, preparado para traspasar a la figura femenina con una espada. La mujer aparece inmovilizada. Con una mano está sujeta al emperador para no caerse mientras levanta la otra en un intento de protegerse. Claudio la sujeta por el cabello para indicar de un modo iconográfico que la tiene sometida, vencida y controlada.

En esta imagen (Fig. 5), semejante a la primera, se observa al emperador Nerón ejerciendo el poder, la victoria y la dominación sobre Armenia, otra de las naciones conquistadas por el Imperio romano. En el relieve, Nerón está sosteniendo a la mujer en una posición desnuda, derrotada y humillada. Él la sujeta firmemente con el brazo izquierdo para que no se derrumbe totalmente, pero con la otra mano empuña su espada desenvainada.

\footnotetext{
9 Ver Hölscher, 2004; Domínguez, 2017.
}

10 El Sebasteión fue construido en el siglo I en honor del emperador Augusto y ampliado con imágenes de sus sucesores. Se encuentra situado al sudoeste de la actual Turquía (Asia Menor). Ver Smith (1978: 88-138). 


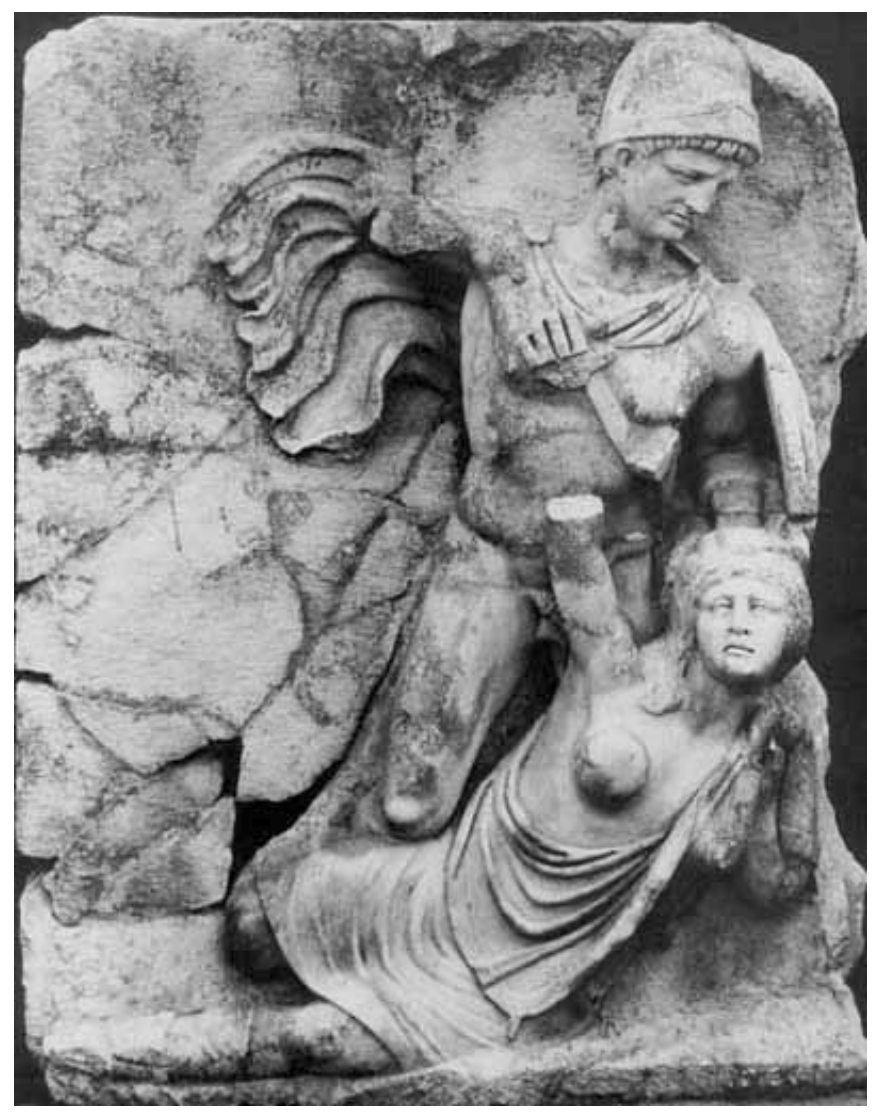

Figura 4. Relieve de Claudio y Britania. En la imagen el emperador Claudio está dominando a Britania, personificada en el cuerpo de la mujer en el Sebasteion de Afrodisias. Fuente: Davina López (2008: 136).

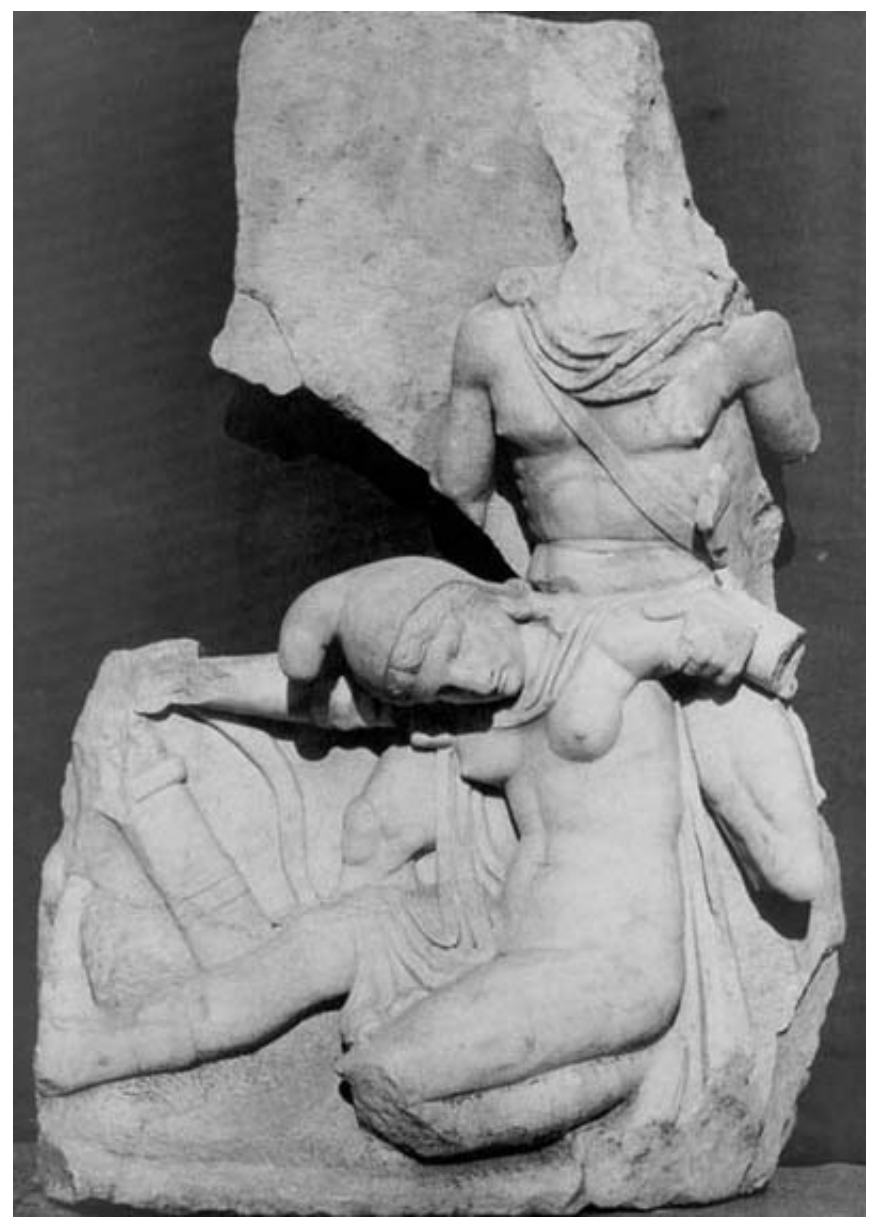

Figura 5. El emperador Nerón victorioso sobre la personificación femenina de Armenia en el Sebasteion en Afrodisias. Fuente: Davina López (2008: 43).
Ambas imágenes reflejan la conquista del poder masculino sobre el cuerpo vulnerable de la mujer, pero sin llegar al aniquilamiento. Las mujeres permanecerán calladas y sumisas bajo el control del emperador y este ascenderá a una categoría de honor, ejerciendo el poder a través de la subordinación de los otros.

Ahora bien, cabe preguntarse por qué precisamente el cuerpo desnudo de la mujer es el "símbolo natural" y, por ello, adecuado, para representar visualmente a las naciones conquistadas militarmente por el poder imperial o por qué no eligió el poder imperial romano la imagen de un varón desnudo y caído para simbolizar la derrota de Armenia o Britania; en definitiva, qué plus de significatividad ofrece el cuerpo desnudo y caído de la mujer para ejemplificar el dominio y el poder invencible de Roma.

El primer significado del cuerpo caído y desnudo de la mujer es la derrota (caído), la humillación (desnudo) y su total indefensión. La mujer desnuda se enfrenta a la espada de un emperador erguido (dominador), fuerte (los relieves resaltan la musculatura del varón, que también puede apreciarse en la coraza de Augusto), orgulloso (la agarra del pelo) e invulnerable. Estas imágenes son un mensaje muy claro a todos los habitantes de las distintas naciones del imperio: están tan desprotegidos e indefensos ante el poder militar del imperio como las mujeres, símbolo de la conquista.

Pero la pregunta inicial sigue en pie: ¿y por qué no el cuerpo de un varón desnudo y caído? Aquí entran en juego toda una serie de elementos que han formado parte de todas las guerras de la historia de la humanidad. Se trata de acciones tendentes a humillar, aterrorizar y paralizar al enemigo ya vencido y conquistado. Son acciones terribles, con las que se vacía de humanidad al vencido y se le trata como un objeto de diversión, venganza y disfrute.

Suelen tipificarse como "crímenes de guerra". Pero esa expresión no refleja fielmente en qué consisten dichas acciones, puesto que un crimen es una acción contra derecho y punible (lo que produce de forma inmediata el sentimiento de que el orden legal es, al fin y al cabo, el marco que impera, incluso dentro de un conflicto armado). Un "crimen" hace referencia, además a algún tipo de acto, más o menos aislado y cometido por una o varias personas.

Pero las violaciones masivas de las mujeres de los soldados vencidos en batalla son una constante de todas las guerras. No se trata de crímenes aislados, sino de una estrategia consentida $-y$ en muchos casos directamente organizada por las estructuras de poder político y militarcon la finalidad de aniquilar moralmente al enemigo vencido. La violación de las mujeres y niñas de los vencidos se realiza, generalmente, en masa y públicamente (a ser posible delante de los padres y maridos). Además, se realiza grupalmente, por grandes grupos o cuadrillas de soldados armados, en una especie de orgía de sexo y delirio de poder.

Porque la finalidad de la violación de la mujer como arma de guerra no es primariamente la satisfacción de una pulsión sexual, sino la exhibición de dominio y poder: la humillación y completo sometimiento de los varones vencidos, a través de la profanación de aquel bien que les es más preciado: sus esposas e hijas. La violación como arma de guerra es un mensaje para los varones vencidos: "sois débiles e inútiles. No habéis sido capaces ni siquiera de defender a vuestras mujeres": 
Históricamente los ejércitos violan a las mujeres para humillar a los varones del ejército contrario despojándolos de su valorada propiedad. Una mujer violada es una propiedad devaluada y es la marca de la derrota para los varones que no pudieron protegerla. La violación es, por lo tanto, un medio para establecer jurisdicción y conquista que, al mismo tiempo que contamina y ocupa el territorio de una nación, transgrede las fronteras de la humanidad, humillando y sometiendo a los derrotados. La violación es un crimen de dominación, y de lo que trata la guerra precisamente es la dominación: aparentemente no tiene nada que ver con la presencia de prostitutas $u$ otras mujeres disponibles, con la que muestra que no se relaciona con el deseo sexual. (Moreno, 2002: 108-109).

Naturalmente, por debajo de estas violaciones de guerra, subyace una antropología según la cual la mujer es objeto de posesión del varón. En la literatura judía deuteronómica puede leerse el noveno mandamiento que Yahvé dio a Moisés: "No codiciarás a la mujer de tu prójimo, ni a su buey, ni su mula, ni su asno" (Ex 20,17). La mujer es un bien equiparable al resto de las posesiones del varón. Es objeto de posesión, antes que sujeto de convivencia. Y por eso puede ser utilizada como símbolo -objeto de transferenciade una humillación al varón posesor de la misma.

La iconografía imperial romana, a través de la imagen de la espada desenvainada apuntando al cuerpo de la mujer desnuda, posee toda su fuerza porque evoca precisamente ese acto de violación de guerra con el que el dominador concluye ritualmente la conquista, destruyendo humanamente al enemigo y dándose por satisfecho con una exhibición de poder y dominio casi divinos. No olvidemos que la espada, según la teoría psicoanalítica, es un símbolo fálico. El caso de estos relieves admite, pues, una interpretación no solo en clave de derrota y victoria, sino también en clave de profanación, violación, conquista y divinización del poder patriarcal.

El hecho indica que esta interpretación de la iconografía imperial romana no es una mera conjetura, es que la violación de la mujer como arma masiva de guerra ha sido una constante en todos los conflictos bélicos, a través de toda la historia. Y, es más, en la actualidad asistimos a un aumento y recrudecimiento en el uso de dicha arma:

En las guerras de la década de los 90, la violación se extendió. Una de las nuevas formas de la guerra es utilizar la violación y el asalto sexual contra las mujeres y las niñas como una forma de aterrorizar y de humillar a la población civil. Esto ocurrió en Bosnia; en Ruanda jugó un papel en el genocidio, así como en la supresión de la resistencia en Haití. En Mozambique en 1992, mientras un pueblo era ocupado por una guerrilla de derecha, cada mujer y cada niña fueron atacadas sexualmente. En la limpieza étnica de Kosovo, las violaciones fueron comunes. Informaciones sobre los procesos de guerra en Liberia, Sierra Leona, Burundi, Argelia, Indonesia, Cachemira y Burna, hablan de la violación y el asalto sexual como una práctica de guerra (Moreno, 2002: 109).

Esto muestra con claridad que la utilización del cuerpo desnudo y vencido de la mujer, como símbolo del poder del varón conquistador, no es algo propio y exclusivo de la iconografía o la propaganda imperial romana. Es un significado que descansa en un auténtico sistema de opresión ideológica patriarcal, de carácter estructural, que se ha ido reforzando a lo largo de los siglos bajo distintas representaciones simbólicas y visuales.

\section{La representación masculina}

Así como las mujeres estaban representadas en posición inferior o subordinada, por el contrario, los varones aparecen simbolizados como personajes divinizados, legitimando su autoridad y control social en los espacios públicos. La estatua de la coraza del emperador Augusto revela la victoriosa y omnipotente masculinidad divinizada, expresada por su cuerpo fuerte y robusto ${ }^{11}$.

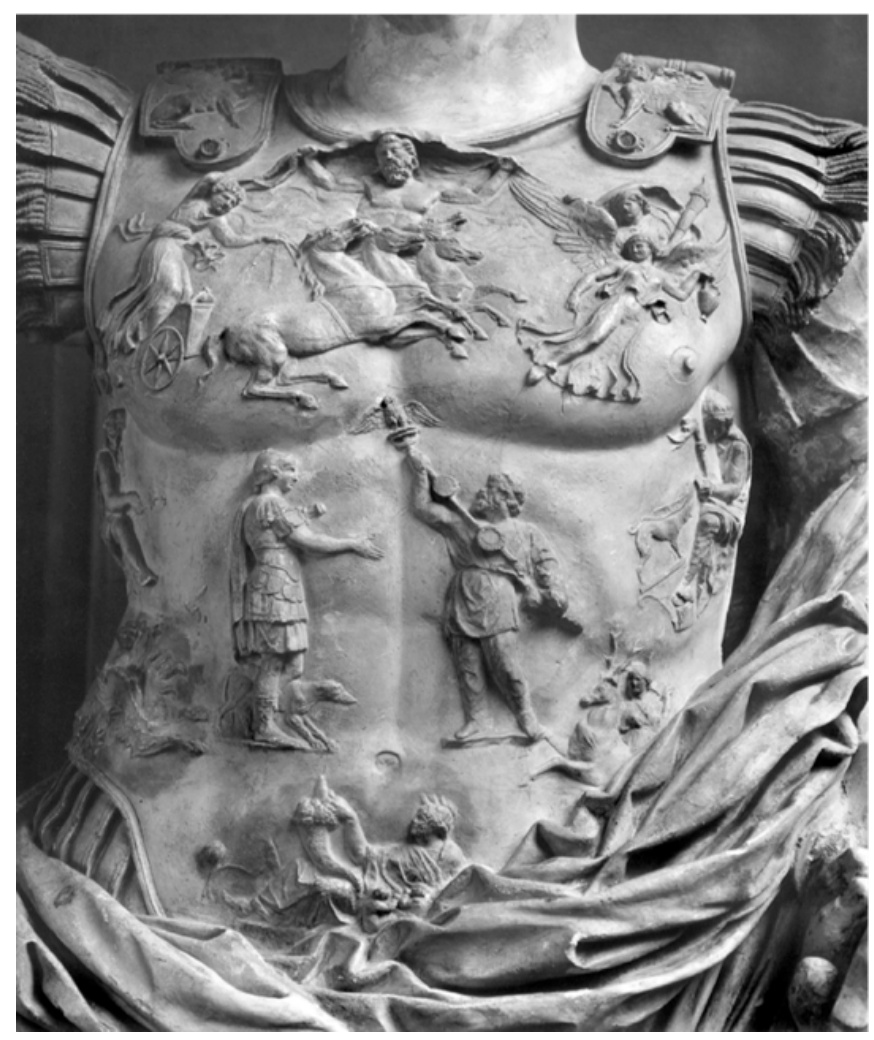

Figura 6. Detalle de la estatua de la coraza de Augusto de Prima Porta Braccio Nuovo. La iconografía hace referencia a la ideología de la victoria imperial. Fuente: Zanker (1992: 227).

Como se puede apreciar en la coraza, la escena del relieve está enmarcada en el Cosmos, entre el cielo y la tierra, representando a las divinidades con sus facetas antropomórficas y cósmicas. En la parte superior aparece la representación de la diosa del cielo (Caelus) sujetando un manto. En el centro del relieve aparece el rey de los partos entregando el águila de la legión y los estandartes a una persona en actitud militar. A la derecha e izquierda aparecen dos mujeres vestidas de trajes tradicionales que representan los grupos étnicos personificados (Hispania y Galia). Ambas están sentadas y en actitud doliente. Bajo la escena central,

\footnotetext{
11 La coraza que puede verse en la estatua de Augusto fue utilizada como un programa iconográfico para comunicar la nueva concepción de la victoria imperial. Representaba el más importante reconocimiento honorífico de la victoria y la paz del emperador sobre todas las naciones conquistadas. El relieve alude directamente a la victoria romana sobre los partos del año 20 a. C. como el último paso hacia el estado universal perfecto (Zanker, 1992: 227-228).
} 
subyace la diosa de la tierra (Tellus), celebrando la paz, tumbada con el cuerno de la abundancia y dos niños junto al vientre. Lleva una corona de espigas. La imagen evoca la fecundidad y la abundancia (Zanker, 1992: 209-211).

A la izquierda, junto al personaje militar, aparece Apolo cabalgando en un grifo; a la derecha, junto a las piernas del rey de los partos, yace Diana montada en una cierva. Ambos están relacionados con las divinidades estelares. Por encima de Apolo aparece en su carro la divinidad Sol y sobre Diana aparece la Luna. Entre ambos, Caelus extiende la cubierta del firmamento. La Luna aparece de medio cuerpo, ya que se encuentra eclipsada por la figura alada de la Aurora, que, con su jarrón, va vertiendo el rocío matutino. La ascensión y ocaso de las divinidades estelares hacen referencia a su eterna existencia.

El cuerpo divinizado del emperador representa lo correcto y lo bueno del mundo. Por su exaltación y su divinidad lo convierte en mediador entre el mundo del más allá y el mundo del más acá; lo incontrolable y lo controlable. La masculinidad divinizada es central para fortalecer la estabilidad del orden cósmico. La paz romana depende de unas relaciones de dominación y subordinación que son expresadas visualmente para naturalizar el poder en las relaciones entre varones y mujeres, incluyendo los cuerpos pasivos de ellas.

Otra de las imágenes que ilustra la posición superior del varón sobre las naciones conquistadas es la "copa del tesoro boscoreale". La imagen ilustra la personificación alegórica de la ideología imperial en que el emperador aparece dominando el mundo ${ }^{12}$.

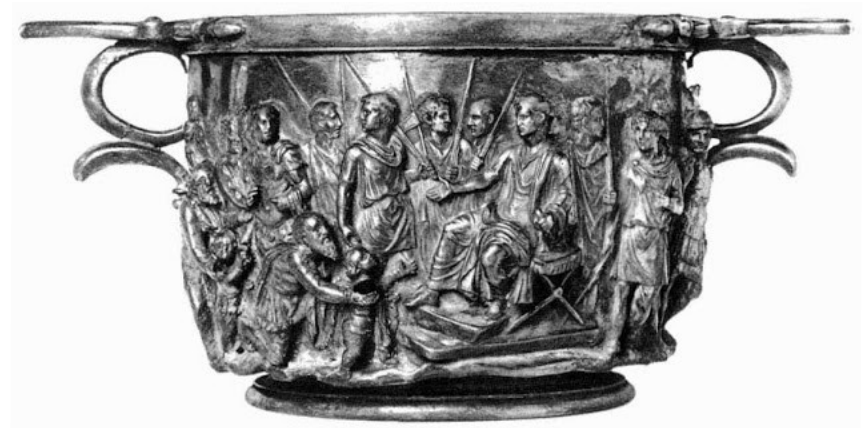

Figura 7. La copa de oro del tesoro boscoreale. En la imagen aparece Augusto capturando a los bárbaros. Fuente: Zanker (1992: 269).

En la escena del relieve aparece el emperador sentado sobre un pedestal, rodeado por oficiales militares. A su derecha se puede apreciar al dios Marte, que personifica la conquista sobre las naciones. Emergen también unos personajes bárbaros que vienen a presentarle voluntariamente sus niños al emperador; este les acoge con benevolencia, compasión y acepta bondadosamente su sometimiento. Las personas se humillan ante él y le reconocen su poder. Estos son, a su vez, amparados y protegidos por Augusto (López, 2008: 49). Se trata, por tanto, de una visión del mundo lleno de la bienaventuranza romana.

La imagen divinizada del emperador garantiza el equilibrio del cosmos a través del sometimiento y la

12 La copa de boscoreale es un recipiente que visualiza la victoria y el dominio divino del emperador Augusto sobre los galos (Zanker, 1992: 270). humillación. El icono del varón se manifiesta con victoria y dominación; lógicamente no se manifiesta ni con debilidad ni pasividad. Esta condición divina del emperador es la que va a exigir a los subyugados el movimiento inverso, la humillación y el sometimiento, para poder acogerlos, pero siempre manteniendo la distancia.

Como se ha podido ver, las representaciones visuales no solo contribuían a reforzar el orden cósmico y social, sino que además permitían diferenciar las relaciones sociales entre varones y mujeres, libres y esclavos, colonizadores y colonizados, cosmos y caos. El restablecimiento del orden y la paz del Imperio dependían, por tanto, de las relaciones de dominación y subordinación, expresado a través de la naturalización de las relaciones del poder entre varón y mujer.

Las imágenes revelan que la ideología institucional romana se consolidó desde la subjetividad y los cuerpos vulnerables de las mujeres. Dicho en otras palabras, el cuerpo de las mujeres sometidas no solo sirvió para hacer énfasis en la superioridad de la victoria de las naciones conquistadas, sino que también contribuyó a reforzar la masculinidad y el poder imperial romano (Kahl, 2010).

El sistema de representación patriarcal representa constantemente al varón como sujeto, impidiendo la subjetividad a la mujer. La mujer, al estar en una posición pasiva, aparece no como sujeto, sino como objeto (o nosujeto). De su cuerpo se ha apropiado el orden patriarcal en una sociedad en la que la representación tiene el poder de construir identidades. Estas personificaciones han influido notablemente en la configuración de un imaginario colectivo de modelos identitarios estereotipados, generando comportamientos, roles y conductas jerarquizadas entre sus miembros.

\section{CONCLUSIONES}

\section{La representación visual y su impacto social}

El poder que determinados grupos e instituciones otorgan a los recursos visuales se sustenta en el recurso a la información para la generación del universo simbólico que, como apuntan Peter Berger y Thomas Luckmann, proporciona legitimación al orden institucional "concediéndole la primacía en la jerarquía de la experiencia humana"13. Para ambos autores, el universo simbólico tiene un carácter nómico y ordenador que proporciona una amplia integración de todos los procesos institucionales, objetivando y legitimando la realidad (Berger y Luckmann, 2005: 131-133). Es lo que, en filosofía del lenguaje, se denomina "performatividad".

El poder de las representaciones visuales deriva de categorías mentales que otorgan significados a nuestras percepciones; es el, así llamado, "conocimiento organizado". La representación visual está vinculada al uso de la palabra pública y a las personas y grupos que consiguen que su

\footnotetext{
13 Para estos autores el universo simbólico comprende una estructura de significados que dotan a la realidad socialmente construida de legitimidad. Así, por ejemplo, el rol de las mujeres en las sociedades patriarcales queda legitimado por explicaciones simbólicas del tipo del relato de Adán y Eva. Esos relatos integran un sistema de símbolos que intentan no solo explicar los roles de las mujeres y varones, sino también los patrones de conducta socialmente aceptados como válidos (Berger y Luckmann, 2005: 121-122).
} 
discurso sobre la realidad acabe siendo aceptado y asumido por la mayoría. Las imágenes y los discursos sobre ellas, por su poder simbólico, dan consistencia a la ideología dominante ${ }^{14}$. Señalar visualmente lo que es correcto o incorrecto, lo normal o lo anormal, es una de las principales estrategias de los grupos de poder.

Ahora bien, el poder de las imágenes como instrumento legitimador de la dominación no puede ejercerse sin el apoyo de aquellos que lo sufren. La violencia simbólica o "violencia epistémica"15, ejercida por los sectores dominantes, cuenta con el apoyo inconsciente de los afectados. Los agentes sociales dominantes y los mismos dominados se encuentran en una relación oscura de adhesión casi corporal, pues el poder de las formas simbólicas solo se ejerce sobre los que han sido preparados para creer en ellas (Bourdieu, 2004). El poder simbólico implica cierta complicidad activa por los que se someten a sus efectos (Fernández, 2005).

\section{Re-imaginando nuevas formas de representación visual}

El análisis visual de las imágenes permite mostrar diferentes construcciones ideológicas del imperio romano en el contexto del siglo I y, al mismo tiempo, visibilizar qué tipo de identidades fueron excluidas de su representación. Esta amplia y variada literatura iconográfica posibilita examinar de forma gráfica la complejidad e interconectividad de las relaciones jerárquicas de género, etnia, sexualidad, estatus y su impacto en la estructuración asimétrica respecto de los géneros.

Las imágenes revelan que la ideología patriarcal imperial romana se consolidó desde la subjetividad y los cuerpos vulnerables de las mujeres. Pero también se ha mostrado cómo la simbología del cuerpo cosificado de las mujeres ha contribuido y contribuye actualmente a reforzar el poder de la masculinidad, incluso en los regímenes democráticos aparentemente más avanzados.

Se legitimó el sistema patriarcal y se ejerció la violencia simbólica sobre el cuerpo de las mujeres en el imperio Romano. Este tipo de violencia ha tenido y sigue teniendo un enorme impacto en la configuración y estructuración de las identidades masculinas y femeninas. Consideramos que detrás de las imágenes se oculta una historia materializada y objetivada que necesita ser visibilizada para poder ser reinterpretada y transformada.

Quizá lo más importante del estudio sea que pone al descubierto un mecanismo de legitimación simbólica sobre la violencia contra el cuerpo de la mujer, de carácter sistémico, global y estructural:

Teniendo como punto de partida las constantes y persistentes violencias, la impunidad y la tolerancia social y estatal de la violencia contra las mujeres, se podría formular como hipótesis que la intervención de los Estados (en general)

\footnotetext{
14 Sobre la relación entre el discurso y el poder simbólico, puede verse Lincoln, 1993.

15 La violencia epistémica es una violencia oculta, no transparente, que tiende a invisibilizar al "otro", expropiándolo de su posibilidad de representación. En concreto, el lenguaje, los símbolos y los discursos codifican este tipo de violencia, que se construye sobre una determinada visión ideológica. Por tanto, para que la violencia epistémica funcione, se necesita de un paradigma intelectual en la que el otro se vea como algo menos humano y deficiente por naturaleza (Spivak, 1994: 82).
}

no está orientada a poner fin a las violencias; ni siquiera a disminuir sus consecuencias e impactos, sino a colocar límites a las expresiones más crueles e inhumanas de ellas: aquellas que en el plano político y simbólico son inaceptables en la sociedad moderna. En esta misma dirección es importante analizar por qué el interés en la violencia contra las mujeres en una sociedad en la cual persisten las estructuras sociosexuales patriarcales; sin desvalorizar los aspectos positivos de este cambio, dicho interés puede responder a una nueva orientación en la interpretación y tratamiento de las violencias contra las mujeres. Interpretación que progresivamente se relaciona con los impactos en la economía, en la salud pública y en la funcionalidad o disfuncionalidad de las relaciones en las familias. La violencia contra las mujeres queda, así, situada en el campo de la relación gobierno-poblacióneconomía política y, por ello, debe ser auto-regulada por el Estado como lo es la fertilidad, la sexualidad o la enfermedad (Sánchez, 2008: 93).

\section{Transformación social y autocrítica}

Las representaciones visuales ofrecen un campo alternativo y abierto al cuestionamiento de las identidades hegemónicas y la exhibición de identidades minoritarias. Al mismo tiempo, requieren de un cambio metodológico a la hora de afrontar su investigación y análisis. E, incluso, una responsabilidad "política", si admitimos la indiscutible influencia de nuestra cultura visual en los regímenes políticos y estamentos sociales actuales; así como en la construcción del imaginario social y cultural.

Consideramos que es necesario introducir un nuevo "marco epistemológico" que nos permita abordar las construcciones identitarias del conocimiento en la cultura visual contemporánea, revisando las bases filosóficas y generando propuestas "epistemologías alternativas" en los estudios de las ciencias humanas y sociales que favorezcan un mejor conocimiento del amplio y complejo estudio de las representaciones visuales del género. Thomas Kuhn advierte de que, cuando un paradigma ya no logra solventar las preguntas que lo articularon, ocurre una revolución científica, que supone un cambio de estrategia (Kuhn, 2005).

Por consiguiente, el desafío fundamental para una ética feminista es el de re-imaginar nuevas formas de representación. Es verdad que desde hace más de tres décadas la crítica feminista ha buscado comprometerse y construir a partir de la diversidad de las cosmovisiones y ser sensible a las políticas de representación. No obstante, un enfoque más ético exige asumir el peso de la representación y que se conozcan los efectos que la violencia epistémica ejerce sobre los cuerpos más vulnerables. Nuestras asimetrías e injusticias nos fuerzan a ver los límites de nuestra definición de lo humano y nos obligan, al mismo tiempo, a corregir dichas injusticias, puesto que podemos entender su significado.

\section{REFERENCIAS}

Alcalá Galán, Mercedes. 2012. Ideología y violencia sexual: el cuerpo femenino subyugado según Rubens y Cervantes. eHumanista/Cervantes 1: 1-40.

Aristóteles. 1994. Metafísica. Madrid: Gredos.

Bartman, Elizabeth. 1999. Portraits of Livia. Imaging 
the Imperial Woman in Augustan Rome. Cambridge: University Press.

Bauman, Richard. 1994. Women and politics in Ancient Rome. Londres: Routledge.

Beckman, Martin. 2012. Diva Faustina. Coinage and Cult in Rome and the Provinces. New York: American Numismatic Society.

Berger, Peter y Luckmann, Thomas. 2005. La construcción social de la realidad. Buenos Aires: Amorrortu.

Bourdieu, Pirre. 2004b. Intervenciones 1961-2001. Ciencia social y acción política. Marsella: Hiru y Ciencias Sociales.

Butler, Judith. 2007. El género en disputa: el feminismo y la subversión de la identidad. Barcelona: Paidós.

Caballero, Antonio. 2004. Comunicación y subversión: estudios de género desde la cultura visual. Aportes de la Teoría Queer y los Estudios Visuales. Journal de Comunicación Social, 2: 95-117.

Carroll, Margaret D. 1989. The Erotics of Absolutism. Rubens and the Mystification of Sexual Violence. Representations, 25: 3-30.

Domínguez, Almudena (ed.). 2010. Mujeres en la Antigüedad clásica. Género, poder y conflicto. Madrid: Sílex.

Domínguez, Almudena. 2017. Imágenes del poder en la Roma imperial: política, género y propaganda. Arenal, 24: 99-131.

Fernández, Juan Manuel. 2005. La noción de violencia simbólica en la obra de Pierre Bourdieu: una aproximación crítica. Cuadernos de Trabajo Social, 18: 7-31.

González, Alberto. 2001. Moneda y guerra en el reinado de Constancio II (337-61). ARQUEO UCA, 1: 115-128.

Greimas, Algirdas y Courtés, Joseph. 1982. Semiótica. Diccionario razonado de la teoría del lenguaje. Madrid: Gredos.

Guasch, Anna María. 2004. Doce reglas para una nueva academia: la nueva historia del arte y los estudios audiovisuales. En Brea, José Luis (ed.) Estudios visuales: la epistemología de la visualidad en la era de la globalización, 59-74. Madrid: Akal.

Hölscher, Tonio. 2004. The language of images in roman art. New York: Cambridge University Press.

Kahl, Brigitte. 2010. Galatians Re-imagined. Reading with the eyes of the vanquished. Minneapolis: Fortress Press.

Kuhn, Thomas. 2005. La estructura de las revoluciones científicas. Madrid: Fondo de Cultura Económica de España.

Lincoln, Bruce. 1993. Discourse and the construction of society. Comparative studies of myth, ritual, and classification. USA: Oxford University Press.

López, Davina. 2007. Before your very eyes: Roman imperial ideology, gender constructs and Paul's inter-nationalism. En Penner, Tood y Vander Stichele, Caroline (eds.) Mapping Gender in Ancient Religious Discourses, 134135. Leiden: Brill.

López, Davina. 2008. Apostle to the Conquered. Reimagining Paul's Mission. Minneapolis: Fortress Press.

Martínez López, Cándida.1998. EireneyPax.Conceptualización y prácticas femeninas en las sociedades antiguas. Arenal, 5(2): 239-261.

Moreno, Hortensia. 2002. Guerra y género. Debate feminista, 25: 108-109.

Páramo, Pablo y Burbano, Andrea. 2011. Género y espacialidad: análisis de factores que condicionan la equidad en el espacio público urbano. Universitas Psychologica, 10(1): 61-70.

Parker, Rozsika y Pollock, Griselda. 2013. Old Mistresses. Women, Art, and Ideology. I. B. Tauris: London.

Prudence, Allen. 1985. The Concept of Woman. The Aristotelian Revolution, 750 B. C. - A. D. 1250. Grand Rapids: Eerdmans.

Robbins, Vernon y Melion, Walter (eds.). 2027. The Art of Visual Exegesis: Rhetoric, Texts, Images. Atlanta: SBL Press.

Sánchez, Olga Amparo. 2008. La violencia contra las mujeres en una sociedad en guerra. Bogotá: Ruta Pacífica de las Mujeres Colombianas.

Smith, Roland Ralph. 1987. The Imperial Reliefs from the Sebasteion at Aphrodisias. Journal of Roman Studies, 77: 88-138.

Spivak, Gayatri Chakravorty. 1994. Can the Subaltern Speak? En Williams, Patrick y Chrisman, Laura (eds.) Colonial Discourse and Post-Colonial Theory: A reader, 85-100. New York: Columbia University Press.

Wood, Susan. 1999. Imperial Women. A study in Public Images, $40 B C-A D$ 68. Leiden: Brill.

Zanker, Paul. 1992. Augusto y el poder de las imágenes. Madrid: Alianza Editorial. 